\title{
Design of a Blockchain-Based Smart Contract Model for Child Labor Alleviation
}

Senou Mahugnon Rosaire Brice, Institute of Mathematics and Physics, University of Abomey-Calavi, Cotonou, Benin Jules Degila, Institute of Mathematics and Physics, University of Abomey-Calavi, Cotonou, Benin

\begin{abstract}
The achievements of west and central Africa in producing more than $60 \%$ of the world's cocoa, and sub-Saharan Africa's achievement in producing $13 \%$ of the world's cotton, hide child labor. These significant levels of production often involve child exposure to issues such as a lack of education; pesticides; dangerous farming tools; work accidents; human trafficking; etc. Blockchain offers an immutable register that allows for digital transactions, smart contract creation, as well as end-to-end product traceability. The main aim of this article is to provide an intelligent contract framework that protects child labor in farming while further enlightening understandings of adoption-related challenges. This framework considers conditions that farmer associations need to satisfy and gives them a tool to improve children's welfare. A research model for the adoption of this tool has been proposed and validated through surveys in the cotton and cacao sectors.
\end{abstract}

\section{KEYWORDS}

Acceptation Issues, Blockchain, Central Africa, Child Work, Cocoa, Cotton, Digital Ledger, Intelligent Agreement, Investigation, West Africa

\section{INTRODUCTION}

The evolution of technologies has given rise to blockchain and smart contracts. The blockchain is a digital ledger that permits the creation of a distributed environment for transactions (Holotescu, 2018). Financial transactions are its first applications. Smart contracts are self-executing contracts that include agreed-upon terms from interested parties. The contracts are written in the form of program codes and are deployed over a decentralized blockchain network. Transactions are thus conducted among anonymous parties without intermediaries (Shuai et al., 2019). In Africa, blockchain technologies have started to emerge in several countries seeking to bring solutions to problems that particularly affect Africans in various ways. Though the continent lacks the infrastructure to implement the technology adequately, organizations still try to use it, given its potential to foster technological revolution on the continent (Koffman, 2019). According to Laghmari (2019), blockchain-based solutions exist and have been used in several countries, including Tunisia, Ghana, Kenya, South Africa, etc.

The agricultural sector represents a vital source of income for African countries. Efforts have been made to improve sector productivity and to promote the social welfare of actors. Those efforts have paid off as, with the Ivory Coast and Ghana (in their becoming the world's leading cocoa

\section{DOI: $10.4018 /$ IJTD.2020070104}

\footnotetext{
This article published as an Open Access article distributed under the terms of the Creative Commons Attribution License (http://creativecommons.org/licenses/by/4.0/) which permits unrestricted use, distribution, and production in any medium, provided the author of the original work and original publication source are properly credited.
} 
producers), and Benin (in its becoming the first cotton producer in Africa) (Africa Food Business [AFD], 2019; Florentin, 2019). However, these achievements are far from being ethically right, as such progress - as has been observed - has come at the significant cost of child labor, which has been documented (KellyAnn, 2019). The governments of Côte d'Ivoire and Ghana have initiated surveys in the cocoa sector. These have revealed that many children had been engaged in unsafe agricultural work. According to Oakes (2019), two (2) million children in Ghana and the Ivory Coast are involved in cocoa production. The cotton industry faces similar issues, where children are recruited or forced to work in the industry for very low pay if any (World Vision, 2012). They encounter unfavorable conditions which include physical misconduct, exposure to dangerous pesticides, and extended work time. This situation affects the sector, as serious investors-before investing-have to comply with industry-governing rules and regulations designed to ensure an ethical supply chain (Oakes, 2019). Therefore, tackling child labor in these sectors became a challenge and is based on raising public awareness and spurring on commitments for allowing children's growth in a safe environment.

From its creation in 2008, blockchain has been used in the agricultural sector (Duncan, 2016). Several properties - such as transparency, immutability, traceability, and security (Olson \& Tomek, 2017) — have favored its adoption. Indeed, immutability properties permit data to not be erased—as the data are permanent once written. Its decentralized architecture increases security, as no one has authority over the system. Its transparency creates trust among actors, leading to a safe business environment. Its traceability is used to combat child labor but requires substantial data storage for video proof recording (Feed the Future [FTF], 2019). It also allows for the following of a cultivated production growth and its journey from the farm to the final product (Duncan, 2016; Oakes, 2019). Due to this, the blockchain properties are, therefore, the main driving forces which make it the first choice to support the use of a smart contract in solving child labor issues. As developing countries suffer from deficient physical and technological infrastructure, the adoption and implementation of the system is much more challenging (FTF, 2019). How can a lightweight application for tackling child labor in the cocoa and cotton sector be designed without using the capability of traceability? What could be the probable resistance to the adoption of this technology?

The main objective of this paper is to provide a Blockchain-based smart contract (BBSC) framework for child labor alleviation along with its probable adoption challenges in the cocoa or cotton sectors. The proposal involves the design of a smart contract application flowchart that considers the participation of several actors of the supply chain to tackle the issue without using the traceability system-therefore eliminating or reducing the need for high data storage. Surveys are carried out, and data are recorded and analyzed for detecting factors that can influence technology adoption in the sectors. The next sections deal with the literature review, research methodology, results and discussion, and conclusion.

\section{LITERATURE REVIEW}

\section{Blockchain Overview}

Blockchain, by definition, is a distributed database that consists of a chain of blocks of information and which makes use of $\mathrm{P} 2 \mathrm{P}$ protocol for interconnecting network nodes and information sharing. The first block of the blockchain is a genesis block, serving as a source for the following blocks in the network with no parent block (Konstantinos \& Michael, 2016). Each transaction is registered, time-stamped, and consecutively widely published with a unique symbol (Ioannis et al., 2018) in the network.

The blockchain network consists of a network of validators called miners, which execute the transaction of any value (Holotescu, 2018; Olson \& Tomek, 2017). Miners work, based on the P2P Nakamoto consensus protocol. The blockchain is replicated by all miners, where each miner proposes their block consisting of new transactions with which to update the blockchain (Luu, Chu, Olickel, 
Saxena \& Hobor, 2016). The P2P consensus, in some contexts, works by selecting a leader among all the miners via a proof-of-work puzzle which broadcasts its proposed block to the rest of the miners. As soon as the proposed block meets a specific requirement, then all the miners update their blockchain to include the new block (Luu et al., 2016).

Blockchain offers several advantages over the database because there is no central authority governing its function and because it provides data transactions without relying on an intermediary, such as a bank, in the case of financial transactions. Bitcoin transaction was its first use, whereas many other potential applications have followed. Figure 1 illustrates a blockchain technology sample:

Figure 1. An example blockchain (adapted from Konstantinos \& Michael, 2016)

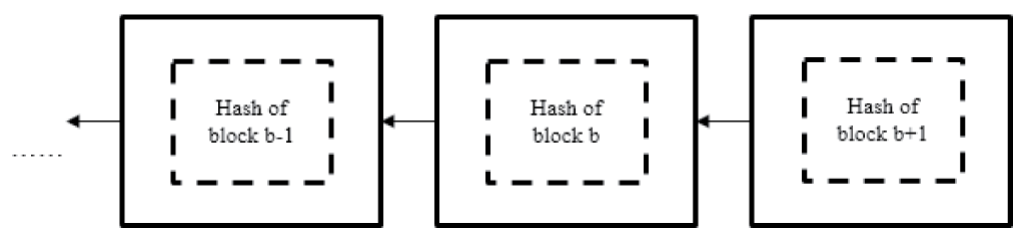

The technology is identified by four main characteristics:

- Immutability

- Distributed Database

- Trustfulness

- $\quad$ Transparency (Holotescu, 2018; Olson \& Tomek, 2017).

\section{Description of a Smart Contract}

A smart contract is a program code identified by an address in the Blockchain network. The main components of the smart contract are a set of executable functions and state variables (Ioannis et al., 2018). Preset-using triggering condition statements (such as "If-Then" statements) are responsible for initiating actions upon meeting/satisfying the given requirements. The agreement of all parties involved in the smart contracts leads to its deployment over the blockchain. Transactions are broadcast via the Peer-to-Peer network, verified by the miners, and are stored in the specific block of the blockchain. The system's incentive mechanism motivates miners, while their computing resources are used for transaction verification. Especially after the miners receive the contract creation or invoking transaction, their local Sandboxed Execution Environment (SEE) - e.g., Ethereum Virtual Machine (EVM) - is used to create a contract or to execute contract code (Shuai et al., 2019). Figure 2 provides an example of a smart contract.

Four (4) different blockchain platforms (Ethereum, Hyperledger Fabric, Bitcoin, and NXT) —each offering distinctive features - are used for the deployment of smart contracts (Alharby \& van Moorsel, 2017; Shuai et al., 2019) with Ethereum being the first choice. The application domains of smart contracts encompass supply chains; real estate; voting systems; banks; digital rights management; etc. (Alharby \& van Moorsel, 2017).

\section{Blockchain and Supply Chain}

Looking at the context of supply chains, recent studies have been investigating the impact of blockchain in supply chains considering several parameters such as cost, risk reduction, flexibility, product quality, and traceability problems (Maciel \& Samuel, 2018). Blockchain improved processes and operations through the entire supply chain, transparently and efficiently, where trust and reliability 


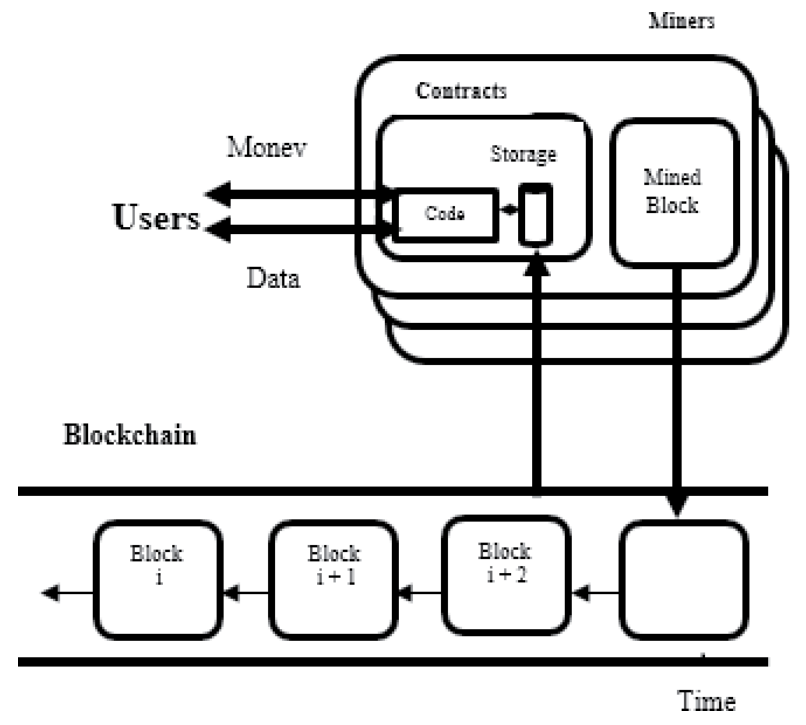

across the network are promoted (Maciel \& Samuel, 2018) with its different properties-namely, immutability, a distributed database, trustfulness, traceability, and transparency (Holotescu, 2018; Olson \& Tomek, 2017). Immutability deals with the impossibility of altering data once it is written in the ledger. The distributed database aspect is related to the possibility of quickly updating anyone who joins the network, as the information is not centralized. Trustfulness allows unknown people to do business without without requiring step-by-step verification of adherence to a complex set of guiding principles. Transparency, which is derived from immutability, allows every transaction to be seen and verified - thereby facilitating its audit.

Therefore, the relationships between stakeholders are strengthened, and product traceability can be significantly facilitated, giving customers the possibility of being made aware of the entire journey of their product. As no intermediary is longer required for transactions, the costs of associated transactions are drastically reduced - thereby augmenting a whole set of advantages (Maciel \& Samuel, 2018).

Smart rural development has found its way via smart contracts, through a revolution in the rural supply and value chain, mostly in the agricultural sector (Gunnar \& Ivan, 2019). According to the same author, paper filling, manual payments, and contract invoices constitute many processes that render the whole agricultural system very inefficient. The digitalization of the chains brings solutions that help in overcoming shortcomings of the rural networks of small and medium enterprises. It leads to optimizing the supply chain and the marketing of products as well as reducing or avoiding dependency on multinational agricultural commodities (Gunnar \& Ivan, 2019).

\section{Technology Model Acceptance (TAMs)}

Technologies arise from different domains but also lead to adoption-related concerns. As such, scholars have tried to develop robust models to comprehend adoption behaviors (Venkatesh, Morris, Davis \& Davis, 2003; Venkatesh, Thong \& Xu, 2012). Davis (1989) proposed the technology acceptance model (TAM), presenting ideas on individual behavior concerning technology acceptance and adoption. Davis proposed with two constructs-namely, Perceived Usefulness (PU) and Perceived Ease of Use (PEOU). These are pillars of other models, especially the Unified Theory of Acceptance and Use of Technology (UTAUT) model (Maciel \& Samuel, 2018). UTAUT, as a proposed by (Venkatesh et al., 2003), resulted from the synthesis of eight other models (Maciel \& Samuel, 2018). In the UTAUT 
model, several constructs were considered as being the ones influencing Behavioral Intention (BI) and technology use (Maciel \& Samuel, 2018). To cope with other realities, a significant extension of the UTAUT - namely, UTAUT2-was realized (Venkatesh et al., 2012). In it, new constructs were included. However, based on the context of the study, this model can be modified to fit additional realities (Maciel \& Samuel, 2018).

\section{RESEARCH DESIGN AND METHODOLOGY}

\section{Research Model and Brief Construct Description}

The proposed solution was evaluated in the field to understand people's awareness and willingness to adopt the technology. The authors proposed a research model based on Technology Acceptance Models (TAM) and UTAUT. TAMs help in understanding the various behaviors of people with regard to their acceptance of technology. Information was derived from the research model proposed by Maciel \& Samuel (2018) for blockchain adoption challenges, with the Unified Theory of Acceptance Use of Technology (UTAUT) (Venkatesh et al., 2003). The UTAUT is a model that has been used in several research fields-mainly in social networking apps and government systems adoption cloud services (Maciel \& Samuel, 2018). Figure 3 represents the authors' proposed research model.

Figure 3. Research model

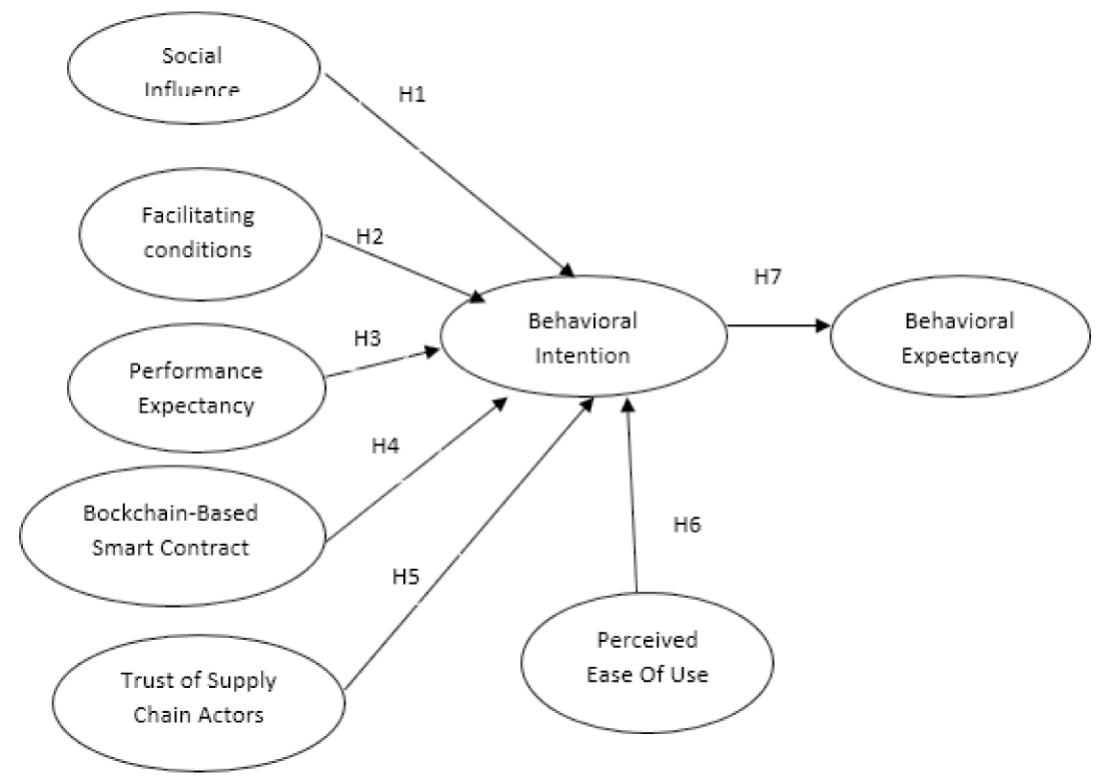

The model proposed consists of several constructs that are within the field of technology adoption and that are derived from the aforementioned study by Maciel \& Samuel (2018). Social influence; the presence of facilitating conditions; performance expectancy; the trust of actors; and the utilization of smart contracts were all identified to be predictors of Behavioral Intention (BI) and Behavioral Expectation (BE) (Maciel \& Samuel, 2018). 


\section{Social Influence}

According to Venkatesh et al. (2003), Social influence (SI) is defined as "the degree to which someone sees that other important people believe he or she should use the new system." For this study, social influence will refer to the extent to which the sector actors understand the importance of why others believe they should use the Blockhain-Based Smart Contract (BBSC) technology. Due to the involvement of several actors in the relevant systems, their interaction creates an influence on adopting the policy. Therefore, the following hypothesis was formed:

H1: Social influence positively affects the behavioral intention to adopt a Blockchain-Based Smart Contract.

\section{Facilitating Conditions}

Facilitating conditions (FC) are essential in UTAUT and are defined as "how far an individual believes that an organizational and technical infrastructure exists to support the system['s] usage" (Venkatesh et al., 2003). Here, it is considered as people's understanding of the available resources for blockchain technology support in enterprises. Previous studies have shown that FC (e.g., computers, internet speed, and integration with other systems) influence the adoption and use of technology (Venkatesh et al., 2003, 2012). Their proposed hypothesis can be restated as follows:

H2: Facilitating conditions positively affect the behavioral intention to adopt a Blockchain-Based Smart Contract.

\section{Performance Expectancy}

Performance expectancy (PEXP) is defined as "the extent to which the new system will help someone so that he/she performs better in the job field" (Venkatesh et al., 2003). It can be defined here as the level to which someone is convinced that the use of BBSC technologies will improve his productivity and well-being. It is mostly related to some advantages (including the useful level) that the technology brings to him/her in the work field (Davis, 1989; Venkatesh et al., 2003). The following hypothesis was proposed:

H3: Performance expectancy positively affects the behavioral intention to adopt a Blockchain-Based Smart Contract.

\section{Blockchain-Based Smart Contract Usage}

A Blockchain-Based Smart Contract (BBSC) is an innovation that suppresses the need for thirdparty involvement in the completion of processes (Shuai et al., 2019). This advantage has increased its implementation in several domains - namely, the domains of supply chain and agriculture-as the technology was proposed to improve processes. Therefore, the authors set forth the following hypothesis:

H4: Blockchain-Based Smart Contract utilization positively affects the behavioral intention to adopt a Blockchain-Based Smart Contract.

\section{Trust of Actors}

Trust can be defined as "the eagerness of a party to endanger itself for the actions of another party while relying on its goodwill to perform a particular action important to the trustor, without any pressure from his [or her] side" (Mayer, Davis, \& Schoorman, 1995) In this context, this can be described as 
Trust of Supply Actors (TSA) stakeholders whereby two or more organizations within the supply chain network agree upon being defenseless to each other while upholding each other's beliefs.

The supply chain network generally lacks transparency among the actors, and an efficient solution is the use of blockchain technologies, as they can reduce uncertainty and increase the transparency and traceability of the entire supply chain (Maciel \& Samuel, 2018):

H5: The trust of actors positively affects the behavioral intention to adopt a Blockchain-Based Smart Contract.

\section{Perceived Ease of Use}

Perceived ease of use, according to Davis (1989), is defined as the extent to which someone admits the use of technology to be effortless. In this context, it is related to the degree of understanding of people about the simplicity of the processes that the system would require in any given sector when in use. Prior literature has demonstrated its usefulness in the adoption of technology (Venkatesh et al., 2003). Therefore, the following hypothesis is derived:

H6: Perceived ease of use positively affects the behavioral intention to adopt a Blockchain-Based Smart Contract.

\section{Behavioral Intention and Expectation}

Contextually, Behavioral Intention is considered as the employee's likelihood to behave in a certain way toward the utilization of Blockchain-Based Smart Contracts (BBSCs); and Behavioral Expectation can be defined as the employee's evaluation of the probability of performing a particular action associated with the use of blockchain in the future.

As shown from past UTAUT studies, the Behavioral Intention construct has a demonstrable impact on the Behavioral Expectation construct (Maruping, Bala, Venkatesh \& Brown, 2017; Venkatesh et al., 2003). Based on this, the researchers propose the following hypothesis:

H7: Behavioral intention positively affects behavioral expectations for Blockchain-Based Smart Contract adoption.

\section{SAMPLE DESIGN AND DATA COLLECTION}

For the validation of the proposed model, surveys were carried out in the cocoa and cotton sectors. The study's purpose was to gather information on Blockchain-Based Smart Contract (BBSC) awareness and adoption prior to the development of an application for child labor reduction. More specifically, the targeted goals were:

- To access players/participants in blockchain technologies and smart contracts; and

- To gauge the field's players' perception and adoption of the smart contract's solution.

A questionnaire was elaborated based on the constructs. Scales were adapted to the given context from prior literature (Maciel \& Samuel, 2018), and responses were measured along a 7-point scale continuum ranging from "strongly disagree" to "strongly agree." The constructs can be found in Table 10 of the Appendix. A pre-survey was conducted by 4 scholars engaged in the field of study of blockchain/smart contract technology.

Appropriately, the field surveys were carried out in the leading cocoa- and cotton-producing countries-namely, the Ivory Coast (surveyed June 24-25, 2019) for cocoa, and Benin (surveyed 
May 14-15, 2019) for cotton. The former is the world's leading producer of cocoa; and the latter is West Africa's leading cotton producer for the 2018/2019 season.

For each crop, 10 people were considered for each category. Three (3) types were then identified for the study—namely:

1. Farmers;

2. Workers or employees; and

3. Exporters/exporters' representatives.

Therefore, 30 people were considered for each crop, for a total of 60 people for the two crops. For each category, their representative was met with; and the overall objectives of the study were clearly explained to them so as to motivate people to participate in the study.

\section{DATA ANALYSIS}

For the data analysis, PLS-SEM was used, as it is one of the prominent tools in the field of social science and supply chain issues regarding the adoption of technologies, where large or small sample sizes can be exploited (Maciel \& Samuel, 2018). Four different sets of data report the actors' categories and peculiarities:

1. Cocoa and cotton producers' data are presented in Table 1;

2. Cocoa and cotton employees' data are presented in Table 2;

3. Cocoa and cotton exporters' data are presented in Table 3; and

4. Cocoa and cotton child labor data for both fields are presented in Table 4.

The findings are as follows:

- In Tables 1, 2, and 3, men are much more involved than women in the sectors;

- The people most engaged in these sectors are 18-25 years old and 34-41 years old in Tables 2 and 3, respectively; while Table 1 shows the engagement of people who are over 40 years of age;

- In terms of experience, the majority of people with the most experience in Table 1 are over 25 years of age; while in Tables 2 and 3, the majority of people with the most experience are less than 15 years of age;

- $\quad$ The educational level of people in Tables 1 and 2 does not exceed the senior secondary level; while in Table 3, the people are instructed up to the Master level;

- In terms of tonnage, the majority of cocoa and cotton farmers each produce from 0 to 5 tons of product;

- Most of the time, cocoa and cotton farmers employ less than 5 employees and cultivate mostly between 0 to 10 Hectares (Ha).

Table 4 summarizes child work in the cocoa and cotton sectors. These results were obtained by asking (of each person who was questioned) 3 types of questions. The questions are:

- What is the age of the children involved in the sector?

- What are the reasons for their involvement?

- What is the work they perform? 
Table 1. Cocoa and cotton producers

\begin{tabular}{|c|c|c|c|c|c|}
\hline \multirow{2}{*}{\multicolumn{2}{|c|}{ Demographics }} & \multicolumn{2}{|c|}{ Cocoa } & \multicolumn{2}{|c|}{ Cotton } \\
\hline & & \multirow{2}{*}{$\begin{array}{ll} & \mathbf{N} \\
9 & \end{array}$} & \multirow{2}{*}{$\%$} & \multirow{2}{*}{$\mathbf{N}$} & \multirow{2}{*}{$\begin{array}{l} \\
\end{array}$} \\
\hline & Male & & & & \\
\hline (2) & Female & 1 & 10 & 3 & 20 \\
\hline \multirow{5}{*}{ Age } & $18-25$ & 0 & 0 & 1 & 10 \\
\hline & $26-33$ & 1 & 10 & 1 & 10 \\
\hline & $34-41$ & 1 & 10 & 1 & 10 \\
\hline & $42-50$ & 1 & 10 & 3 & 30 \\
\hline & $>50$ & 7 & 70 & 4 & 40 \\
\hline \multirow{6}{*}{ Experience (years) } & $0-5$ & 0 & 0 & 1 & 10 \\
\hline & $6-10$ & 0 & 0 & 1 & 10 \\
\hline & $11-15$ & 0 & 0 & 0 & 0 \\
\hline & $16-20$ & 3 & 30 & 1 & 10 \\
\hline & $21-25$ & 1 & 10 & 1 & 10 \\
\hline & $>25$ & 6 & 60 & 6 & 60 \\
\hline \multirow{5}{*}{$\begin{array}{l}\text { Cultivated Area, in } \\
\text { Hectares (Ha) }\end{array}$} & $0-5$ & 2 & 20 & 3 & 30 \\
\hline & $6-10$ & 5 & 50 & 4 & 40 \\
\hline & $11-15$ & 2 & 20 & 1 & 10 \\
\hline & $16-20$ & 0 & 0 & 1 & 10 \\
\hline & $>20$ & 1 & 10 & 1 & 10 \\
\hline \multirow{5}{*}{ Tonnage (T) } & $0-5$ & 9 & 90 & 5 & 50 \\
\hline & $6-10$ & 1 & 10 & 4 & 40 \\
\hline & $11-15$ & 0 & 0 & 0 & 0 \\
\hline & $16-20$ & 0 & 0 & 0 & 0 \\
\hline & $>20$ & 0 & 0 & 1 & 10 \\
\hline \multirow{2}{*}{ Employees } & $0-5$ & 7 & 70 & 8 & 80 \\
\hline & $>5$ & 3 & 30 & 2 & 20 \\
\hline \multirow{6}{*}{ Educational Level } & Illiterate & 4 & 40 & 6 & 60 \\
\hline & Primary & 4 & 30 & 3 & 30 \\
\hline & Secondary & 2 & 30 & 1 & 1 \\
\hline & Bachelor & 0 & 0 & 0 & 0 \\
\hline & Master & 0 & 0 & 0 & 0 \\
\hline & Ph.D. & 0 & 0 & 0 & 0 \\
\hline
\end{tabular}

Source: Field inquiries

From Table 4, children are involved in agricultural work, mainly for traditional inheritance and subsistence reasons. They get injured when performing several tasks including weeding; sowing; harvesting; and spraying pesticides. They also get exposed to pesticides. In both sectors (cocoa and cotton), children above 14 years of age are injured much more severely as compared to those under 
Table 2. Cocoa and cotton employees

\begin{tabular}{|c|c|c|c|c|c|}
\hline \multirow{2}{*}{\multicolumn{2}{|c|}{ Demographics }} & \multicolumn{2}{|c|}{ Cocoa } & \multicolumn{2}{|c|}{ Cotton } \\
\hline & & $\mathbf{N}$ & $\%$ & $\mathbf{N}$ & $\%$ \\
\hline \multirow{2}{*}{ Gender } & Male & 10 & 100 & 8 & 80 \\
\hline & Female & 0 & 0 & 2 & 20 \\
\hline \multirow{5}{*}{ Age } & $18-25$ & 3 & 30 & 4 & 40 \\
\hline & $26-33$ & 2 & 20 & 2 & 20 \\
\hline & $34-41$ & 4 & 40 & 2 & 20 \\
\hline & $42-50$ & 1 & 10 & 1 & 10 \\
\hline & $>50$ & 0 & 0 & 1 & 10 \\
\hline \multirow{6}{*}{ Experience } & $0-5$ & 2 & 20 & 2 & 20 \\
\hline & $6-10$ & 4 & 40 & 3 & 30 \\
\hline & $11-15$ & 2 & 20 & 2 & 20 \\
\hline & $16-20$ & 2 & 20 & 1 & 10 \\
\hline & $21-25$ & 0 & 0 & 1 & 10 \\
\hline & $>25$ & 0 & 0 & 0 & 0 \\
\hline \multirow{6}{*}{ Educational level } & Illiterate & 0 & 0 & 0 & 0 \\
\hline & Primary & 0 & 0 & 0 & 0 \\
\hline & Secondary & 2 & 20 & 3 & 30 \\
\hline & Bachelor & 6 & 60 & 4 & 40 \\
\hline & Master & 2 & 20 & 3 & 30 \\
\hline & Ph.D. & 0 & 0 & 0 & 0 \\
\hline
\end{tabular}

Source: Field inquiries

that age. The percentage obtained in terms of injuries was simply derived from the number of people questioned out of the total in an industry which confirms the involvement of children within a certain age interval.

\section{RESULTS AND DISCUSSION}

This section is divided into two sub-sections:

1. The first section deals with the proposition of a Blockchain-Based Smart Contract (BBSC) flowchart for tackling child labor in the two sectors; and

2. The second section deals with adoption-related challenges and concerns.

\section{PROPOSED SMART CONTRACT APPLICATION FLOWCHART}

The proposed flowchart takes into consideration the results obtained from the authors' survey and provides a contract platform with a set of questions designed to help secure children's well-being as well as to attract investors to invest in farmers. From the inquiries made in the field, cocoa and cotton farmers are grouped into associations or cooperatives for facilitating the management of the sector. 
Table 3. Cocoa and cotton exporters

\begin{tabular}{|c|c|c|c|c|c|}
\hline \multirow{2}{*}{\multicolumn{2}{|c|}{ Demographics }} & \multicolumn{2}{|c|}{ Cocoa } & \multicolumn{2}{|c|}{ Cotton } \\
\hline & & \multirow{2}{*}{$\mathbf{N}$} & \multirow[b]{2}{*}{70} & \multirow{2}{*}{$\mathbf{N}$} & \multirow[b]{2}{*}{80} \\
\hline & Male & & & & \\
\hline Зести- & Female & 3 & 30 & 2 & 20 \\
\hline \multirow{5}{*}{ Age } & $18-25$ & 3 & 30 & 3 & 30 \\
\hline & $26-33$ & 1 & 10 & 2 & 20 \\
\hline & $34-41$ & 4 & 40 & 3 & 30 \\
\hline & $42-50$ & 2 & 20 & 2 & 20 \\
\hline & $>50$ & & 0 & 0 & 0 \\
\hline \multirow{6}{*}{ Experience } & $0-5$ & 4 & 40 & 3 & 30 \\
\hline & $6-10$ & 2 & 20 & 2 & 20 \\
\hline & $11-15$ & 1 & 10 & 2 & 20 \\
\hline & $16-20$ & 1 & 10 & 1 & 10 \\
\hline & $21-25$ & 1 & 10 & 1 & 10 \\
\hline & $>25$ & 1 & 10 & 1 & 10 \\
\hline \multirow{6}{*}{ Educational level } & Illiterate & 3 & 30 & 2 & 20 \\
\hline & Primary & 3 & 30 & 5 & 50 \\
\hline & Secondary & 4 & 40 & 3 & 30 \\
\hline & Bachelor & 0 & 0 & 0 & 0 \\
\hline & Master & 0 & 0 & 0 & 0 \\
\hline & Ph.D. & 0 & 0 & 0 & 0 \\
\hline
\end{tabular}

Source: Field inquiries

Table 4. Child labor

\begin{tabular}{|l|l|l|l|l|}
\hline \multicolumn{1}{|c|}{ Child Usage } & \multicolumn{2}{c|}{ Cocoa } & \multicolumn{2}{c|}{ Cotton } \\
\hline Age (years) & $9-13$ & $14-17$ & $9-13$ & $14-17$ \\
\hline Reasons & Traditional inheritance, subsistence & Traditional inheritance, subsistence \\
\hline Work performed & $\begin{array}{l}\text { Field surveillance } \\
\text { Food/tools intake for } \\
\text { workers, Weeding }\end{array}$ & $\begin{array}{l}\text { Weeding, Sowing, } \\
\text { Harvest, Pesticides } \\
\text { (few) }\end{array}$ & $\begin{array}{l}\text { Field surveillance, Food } \\
\text { intake for workers, } \\
\text { weeding, Sowing }\end{array}$ & $\begin{array}{l}\text { Weeding, Sowing, } \\
\text { Harvest, Pesticides } \\
\text { Utilization }\end{array}$ \\
\hline Injuries & $10 \%$ & $90 \%$ & $15 \%$ & $85 \%$ \\
\hline
\end{tabular}

Source: Field inquiries

There are different responsibility levels that the proposed flowchart takes into account in its design. Figure 4 shows the proposed flowchart.

From the flowchart, a culture or crop is first chosen for analysis. The name of the targeted association is provided, and a questionnaire related to child conditions is made available for CD (Cooperative director), AD (Administrator of Group), SM (Sector Manager), F (Farmer), and E (Employee) for the blockchain to answer. Additionally, other actors such as external /surrounding 


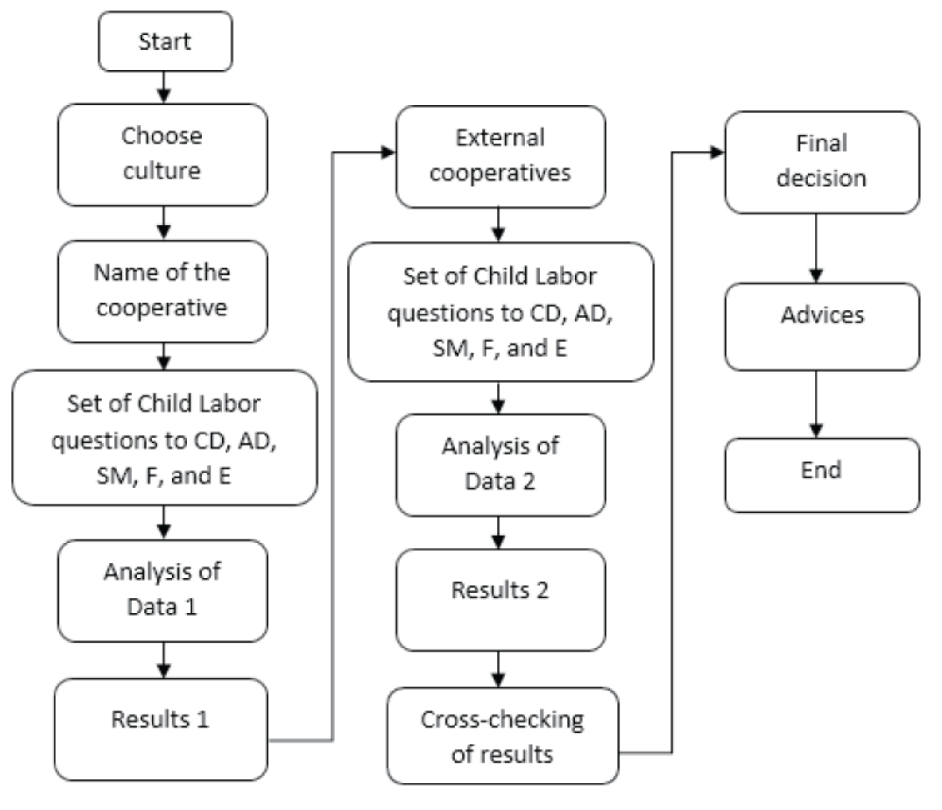

$\mathrm{CD}=$ Cooperative director, $\mathrm{AD}=\mathrm{Administrator}$ of Group, $\mathrm{SM}=$ Sector Manager, $\mathrm{F}=$ farmer, $\mathrm{E}=$ Employee.

cooperatives chosen by the management board are involved in order to challenge the association's answers. Data from the different associations are cross-checked to ensure consistency and truthfulness before a final decision regarding child labor existence or not is made. A favorable ruling will give permission to farmers or the whole cooperative to farm, upon satisfying a minimum requirement where pieces of advice are also offered for guiding the work season in ways designed to ensure a cruelty-free environment.

The execution of this smart contract application intends to provide a secure way of reducing child labor in the cocoa or cotton sector by:

- Promoting righteousness and integrity in the industries;

- Pointing out the need for farmers to have a child-free work season;

- Encouraging farmers to support children's education-encouraging farmers to become more conscious in educating the children and involving them in farming, as passing on the culture is essential to ensuring brighter future, although their help may be required in the sector later in life;

- Strengthening the transparency capability of blockchain to promote a child-free or cruelty-free environment in the production of the harvest season of crops; and

- Allowing farmers to be financed by other investors if their work season is child/cruelty-free.

\section{SMART-PLS DATA DISCUSSION}

To further analyze the gathered data, Smart PLS 3.0 is used (Maciel \& Samuel, 2018). The authors adapted the measurement model from Maciel \& Samuel (2018) and their chosen constructs are well justified for the blockchain technologies context. 
Table 5 shows the outer loadings for the cocoa and cotton crop. It can easily be seen that all have a value higher than the threshold value of 0.7 (Hair, Hult, Ringle \& Sarstedt, 2017) —all except SI1 with a value of 0.611 and PEOU3 with a value of 0.631 in the cocoa and cotton sectors, respectively.

Table 6 displays the Cronbach's alpha values, composite reliability, and AVE values of all constructs. From the literature (Maciel \& Samuel, 2018), their threshold values are 0.70, 0.70, and

Table 5. Outer loading

\begin{tabular}{|c|c|c|c|}
\hline \multirow{2}{*}{ Construct } & \multirow{2}{*}{ Item } & \multicolumn{2}{|c|}{ Loadings } \\
\hline & & Cocoa & Cotton \\
\hline \multirow{3}{*}{$\mathrm{BE}$} & BE1 & 0.844 & 0.938 \\
\hline & BE2 & 0.931 & 0.921 \\
\hline & BE3 & 0.883 & 0.733 \\
\hline \multirow{3}{*}{ BI } & BI1 & 0.895 & 0.767 \\
\hline & BI2 & 0.848 & 0.734 \\
\hline & BI3 & 0.733 & 0.901 \\
\hline \multirow{2}{*}{ BSCU } & BSCU1 & 0.906 & 0.813 \\
\hline & BSCU2 & 0.824 & 0.761 \\
\hline \multirow{4}{*}{ FC } & FC1 & 0.757 & 0.675 \\
\hline & $\mathrm{FC} 2$ & 0.881 & 0.88 \\
\hline & FC3 & 0.763 & 0.811 \\
\hline & $\mathrm{FC} 4$ & 0.898 & 0.781 \\
\hline \multirow{3}{*}{ PE } & PE1 & 0.926 & 0.864 \\
\hline & PE2 & 0.966 & 0.865 \\
\hline & PE3 & 0.853 & 0.775 \\
\hline \multirow{4}{*}{ SI } & SI1 & 0.616 & 0.768 \\
\hline & SI2 & 0.710 & 0.750 \\
\hline & SI3 & 0.915 & 0.872 \\
\hline & SI4 & 0.867 & 0.896 \\
\hline \multirow{3}{*}{ TSA } & TSA1 & 0.861 & 0.900 \\
\hline & TSA2 & 0.766 & 0.800 \\
\hline & TSA3 & 0.829 & 0.710 \\
\hline \multirow{4}{*}{ PEOU } & PEOU1 & 0.825 & 0.861 \\
\hline & PEOU2 & 0.809 & 0.738 \\
\hline & PEOU3 & 0.737 & 0.631 \\
\hline & PEOU4 & 0.943 & 0.720 \\
\hline
\end{tabular}

$\mathrm{BE}=$ Behavioral Expectation, $\mathrm{Bl}=$ Behavioral Intention, $\mathrm{BSCU}=$ Blockchain Supply Chain Usage, $\mathrm{FC}=$ Facilitating Conditions, $\mathrm{PE}=$ Performance Expectancy, PEOU=Perceived Ease of Use, SI=Social Influence, TSA=Trust of Supply Actors.

0.50 , respectively. As all the obtained values are above the threshold value, the use of all constructs in the proposed research is said to be justified. The discriminant validity of the model presents in Table 7 was tested and validated, as the AVE square root of each construct was more significant than the 
Table 6. Cronbach's Alpha, composite reliability, and AVE value

\begin{tabular}{|l|l|l|l|l|l|l|}
\hline \multirow{2}{*}{ Construct } & \multicolumn{2}{|c|}{ Cronbach's Alpha } & \multicolumn{2}{c|}{ Composite Reliability } & \multicolumn{2}{c|}{$\begin{array}{c}\text { Average Variance Extracted } \\
\text { (AVE) }\end{array}$} \\
\cline { 2 - 7 } & \multicolumn{1}{|c|}{ Cocoa } & \multicolumn{1}{|c|}{ Cotton } & \multicolumn{1}{c|}{ Cocoa } & \multicolumn{1}{c|}{ Cotton } & \multicolumn{1}{c|}{ Cocoa } & \multicolumn{1}{c|}{ Cotton } \\
\hline BE & 0.864 & 0.831 & 0.917 & 0.901 & 0.786 & 0.755 \\
\hline BI & 0.723 & 0.771 & 0.840 & 0.815 & 0.641 & 0.600 \\
\hline BSCU & 0.774 & 0.810 & 0.857 & 0.765 & 0.751 & 0.620 \\
\hline FC & 0.845 & 0.774 & 0.896 & 0.851 & 0.684 & 0.591 \\
\hline PE & 0.909 & 0.797 & 0.940 & 0.874 & 0.839 & 0.550 \\
\hline SI & 0.704 & 0.718 & 0.712 & 0.739 & 0.514 & 0.530 \\
\hline TSA & 0.757 & 0.728 & 0.860 & 0.744 & 0.672 & 0.6510 \\
\hline PEOU & 0.851 & 0.749 & 0.899 & 0.829 & 0.839 & 0.551 \\
\hline
\end{tabular}

Table 7. Discriminant value

\begin{tabular}{|c|c|c|c|c|c|c|c|c|}
\hline \multirow{2}{*}{ Construct } & \multicolumn{8}{|c|}{ Cocoa } \\
\hline & 1 & 2 & 3 & 4 & 5 & 6 & 7 & 8 \\
\hline $\mathrm{BE}$ & 0.886 & & & & & & & \\
\hline BI & 0.829 & 0.801 & & & & & & \\
\hline BSCU & 0.658 & 0.731 & 0.866 & & & & & \\
\hline $\mathrm{FC}$ & 0.822 & 0.725 & 0.573 & 0.827 & & & & \\
\hline PE & 0.488 & 0.438 & 0.210 & 0.626 & 0.916 & & & \\
\hline SI & 0.772 & 0.759 & 0.573 & 0.804 & 0.473 & 0.843 & & \\
\hline TSA & 0.833 & 0.799 & 0.784 & 0.763 & 0.524 & 0.685 & 0.820 & \\
\hline PEOU & 0.676 & 0.648 & 0.526 & 0.814 & 0.425 & 0.676 & 0.562 & 0.832 \\
\hline \multicolumn{9}{|l|}{ Cotton } \\
\hline $\mathrm{BE}$ & 0.869 & & & & & & & \\
\hline BI & 0.758 & 0.775 & & & & & & \\
\hline BSCU & 0.623 & 0.844 & 0.787 & & & & & \\
\hline $\mathrm{FC}$ & 0.603 & 0.475 & 0.495 & 0.769 & & & & \\
\hline PE & 0.288 & 0.347 & 0.314 & 0.383 & 0.742 & & & \\
\hline SI & 0.527 & 0.446 & 0.526 & 0.613 & 0.175 & 0.836 & & \\
\hline TSA & 0.624 & 0.478 & 0.540 & 0.656 & 0.198 & 0.690 & 0.727 & \\
\hline PEOU & 0.673 & 0.620 & 0.708 & 0.590 & 0.472 & 0.528 & 0.259 & 0.807 \\
\hline
\end{tabular}

correlations between that particular construct and all other constructs. The path coefficients results+, std. dev., $t$-values, and $p$-values are presented in Table 8 for the structural model regarding each crop.

From the table, it can be seen that SI has a positive non-significant effect on BI ( $\beta=0.172$, $\mathrm{t}=1.147, \mathrm{p}=0.260$ and $\beta=0.023 ; \mathrm{t}=0.081, \mathrm{p}=0.936)$ in both the cocoa and cotton sectors, respectively. Thus: 
Table 8. Path coefficients

\begin{tabular}{|l|l|l|l|l|l|l|l|l|l|}
\hline \multirow{2}{*}{ Hypothesis } & \multirow{2}{*}{ Path } & \multicolumn{3}{|c|}{ Cocoa } & \multicolumn{5}{c|}{ Cotton } \\
\cline { 3 - 11 } & & $\boldsymbol{\beta}$ & $\begin{array}{c}\text { Standard } \\
\text { Deviation } \\
(\text { SD })\end{array}$ & T-Statistics & P values & $\boldsymbol{\beta}$ & $\begin{array}{c}\text { Standard } \\
\text { Deviation } \\
(\text { SD) }\end{array}$ & T-Statistics & P Values \\
\hline H1 & SI $\rightarrow$ BI & 0.172 & 0.287 & 1.147 & 0.260 & 0.023 & 0.202 & 0.081 & 0.936 \\
\hline H2 & FC $\rightarrow$ BI & -0.113 & 0.263 & 0.083 & 0.934 & 0.083 & 0.160 & 0.410 & 0.685 \\
\hline H3 & PE $\rightarrow$ BI & 0.068 & 0.158 & 0.202 & 0.841 & -0.052 & 0.165 & 0.208 & 0.837 \\
\hline H4 & BSCU $\rightarrow$ BI & 0.223 & 0.171 & 1.389 & 0.175 & 0.784 & 0.199 & 4.062 & 0.000 \\
\hline H5 & TSA $\rightarrow$ BI & 0.417 & 0.308 & 1.114 & 0.274 & -0.025 & 0.214 & 0.094 & 0.926 \\
\hline H6 & PEOU $\rightarrow$ BI & 0.262 & 0.252 & 0.313 & 0.757 & 0.092 & 0.124 & 0.646 & 0.523 \\
\hline H7 & BI $\rightarrow$ BE & 0.824 & 0.034 & 24.535 & 0.000 & 0.751 & 0.084 & 8.969 & 0.000 \\
\hline
\end{tabular}

- H1 was not supported for either crop.

FC has a negative and a positive non-significant effect on BI $(-\beta=0.113, t=0.083, p=0.934$ and $\beta=0.083 ; \mathrm{t}=0.410, \mathrm{p}=0.685)$, respectively, for cocoa and cotton. Consequently, in the two agricultural sectors.

- $\mathrm{H} 2$ was not supported for either crop.

PE was found to have a positive and a negative effect on $\mathrm{BI}(\beta=0.068, \mathrm{t}=0.202, \mathrm{p}=0.841$ and $\beta=-0.052 ; \mathrm{t}=0.208, \mathrm{p}=0.837$ ) in the cocoa and cotton sectors, respectively.

- $\quad$ H3 was not supported for either crop.

For BSCU, a positive non-significant effect on BI $(\beta=0.223, \mathrm{t}=0.171, \mathrm{p}=1.389)$ is observed in the cocoa sector, while a significant positive effect on $\mathrm{BI}$ (and $\beta=0.784 ; \mathrm{t}=4.062, \mathrm{p}=0.000$ ) is observed in the cotton sector. Thus:

- H4 was not supported in the cocoa sector, but $\mathrm{H} 4$ was supported in the cotton sector.

This explains the existence of differences in technology usage and adoption in the cocoa and cotton sectors.

The TSA construct has a positive and a negative non-significant effect on BI $(\beta=0.417, \mathrm{t}=$ $0.114, p=0.274$ and $\beta=-0.025 ; t=0.094, p=0.926)$ in the cocoa and cotton sectors, respectively. This confirms that:

- H5 was not supported for either crop.

The PEOU also has shown positive non-significant effect on BI $(\beta=0.262, \mathrm{t}=0.313, \mathrm{p}=0.757$ and $\beta=0.092 ; \mathrm{t}=0.646, \mathrm{p}=0.523$ ) in the cocoa and cotton sectors, respectively. Thus:

- H6 was not supported for either crop. 
However, BI has been proven to have a strong positive effect on BE in the cotton and cocoa sectors. Therefore:

- $\quad \mathrm{H} 7$ is strongly supported for both crops.

Generally, most of the constructs do not have an effect on the sectors (except for BSCU's effect on the cotton sector).

Lastly, Table 9 shows that the proposed model accounted for 64.9 and 68.0 percent of the variance in BI for cotton and cocoa, respectively; and 55.9 and 67.5 percent of the variance in BE for the same crops, respectively. Considering BI, the obtained variance is close to the benchmarks (Venkatesh et al., 2003, 2012), while the BE results corroborate those by Maruping et al. (2017). The result of the R-square is presented in Table 9.

Table 9. R-square results

\begin{tabular}{|c|c|c|c|c|}
\hline \multirow[t]{2}{*}{ Dependent Constructors } & \multicolumn{2}{|c|}{ Cocoa } & \multicolumn{2}{|c|}{ Cotton } \\
\hline & R-Square & $\begin{array}{l}\text { R-Square } \\
\text { Adjusted }\end{array}$ & R-Square & $\begin{array}{l}\text { R-Square } \\
\text { Adjusted }\end{array}$ \\
\hline $\mathrm{BE}$ & 0.687 & 0.675 & 0.574 & 0.559 \\
\hline BI & 0.747 & 0.680 & 0.722 & 0.649 \\
\hline
\end{tabular}

The R-Square of Behavioral Intention in cocoa and cotton met the literature requirements (Maciel \& Samuel, 2018), which confirms a better model for BBSC adoption.

Our analysis showed that the R-square for cocoa and cotton was 68 and 64.9 percent, respectively, for BI. Also, the BE for the two (2) crops were found to be 67.5 and 55.9, respectively. All this falls within the requirements according to the literature (Maciel \& Samuel, 2018; Joe, Jeffrey, Marko, \& Christian 2019), thus giving credibility to the proposed model for smart contract adoption. Unfortunately, to the best of the authors' knowledge, there is minimal literature related to adoptionrelated challenges associated with BBSC. However, based on the available research including blockchain adoption technology studies and the path coefficient, SI was demonstrated to not have a significant positive effect on BBSC adoption in the cocoa and cotton sectors. This result is in contrast with a recent study of the loan market (Malan \& Steyn, 2019), where SI was found to positively affect smart contract Behavioral Intention, making SI a predictor of BI. This difference can be related to the context in which the studies were conducted and to what extent people in the sectors interacted.

Regarding facilitating conditions (FC), the authors' study reveals that FC does not have much of a positive effect on the adoption of BBSC in the cotton and cocoa sectors. With respect to the prior literature (Joe et al., 2019), this result is confirmed in the market loan field, as FC does not influence the use of Blockchain-Based Smart Contracts (BBSCs). However, Maciel \& Samuel (2018) demonstrated that FC has an influence on the adoption of blockchain technology in the supply chain context, making it a predictor of Behavioral Intention and Behavioral Expectation. This may, to some extent, in rural areas or remote places where there is no access to Internet or similar infrastructure, help explain why developing countries do not always have the necessary conditions for supporting technology adoption.

According to Joe et al. (2019), Performance Expectancy (PE) displays a strong relation with Behavioral Intention. This is not confirmed in the authors' study; since, in the cocoa and cotton sectors, PE was not supported for BBSC adoption. However, in the supply chain context (Maciel \& Samuel, 2018), PE was shown to have a strong positive effect on smart contract blockchain adoption. 
This leads to the conclusion that, with respect to blockchain technologies, PE might have a different impact in a different context.

TSA has no effect on BBSC adoption in the cotton and cocoa sectors, though it is an essential factor in technology adoption. This is confirmed in Malan \& Steyn (2019) and also in the supply chain context (Maciel \& Samuel, 2018). This result may explain the extent to which people are reluctant to rely on technology to settle problems.

The adoption of the technology by Blockchain Supply Chain Users (BSCU) is not supported in the cocoa sector but is supported in the cotton sector, showing that there are differences in the use of the technology among the sector's actors. This may be related to the degree of awareness of the technology in the two industries (Maciel \& Samuel, 2018). Perceived Ease of Use (PEOU) does not influence technology adoption in the cocoa or cotton sectors. Behavioral Expectation (BE) is greatly influenced by Behavioral Intention (BI) in the cocoa and cotton sectors, confirming that BI is a strong predictor of BE.

Although the BBSC in the agricultural field is recent, the results show the existence of different factors affecting technology adoption in the agricultural sector. The BSCU was proven to influence behavioral adoption only in the cotton sector-suggesting that the acceptance of the technology is related to having some ability to manipulate the technology. The non-influence of FC on technology adoption can be related to the lack of knowledge regarding the use of technology. However, the strong influence of BI on BE suggests the need for embracing this technology in the sector, to change people's conditions. As PE does not have a substantial effect on BI, this might also be due to people's lack of awareness of the technology. PE, PEOU, and TSA do not influence technology adoption. This is a contribution to the literature review.

\section{CONCLUSION}

In this document, we proposed a Blockchain-Based Smart Contract (BBSC) application flowchart for child labor reduction while developing a model to enable its adoption in the cocoa and cotton sectors. Surveys were carried out to assess child labor issues in the industry. The result is the proposal of an application based on collaborative work involving key players. The proposed research model has been validated using PLS-SEM to gauge the adoption of the technology.

The proposed application will promote a cruelty-free environment in the agriculture sector. It involves all the payers; and it will influence policies for the targeted sectors. The model provides the literature on BBSC application and adoption with valuable insights that can help scholars and practitioners better understand, and contribute to the evolution of, the research on individuals' behavior when adopting the technology. As an important outcome, the application appears very helpful and will positively impact people's behavior. Further studies can apply the same model to other crops, while considering the crops' various distinctive characteristics. Moreover, research can be conducted to find out how other constructs could have had a significant impact on BBSC adoption in the agricultural sector.

Important next steps include application development and efficiency testing. It is expected that this study will also help managers as well as policy makers be even better informed as to opportunities, as well as related challenges, while implementing such technology. As BSCU was found to influence BI, BBSC adopters had to find a way to facilitate its usage. This may involve training and coaching people.

Finally, the proposed smart contract application can allow farmers or associations to be financed by investors and can promote an ethical supply chain. It will enable policymakers to better regulate both sectors. One must pay attention to smart contract securities issues. Further research will address smart contract security concerns; discuss currently adequate state-of-the-art approaches; review the leading solutions; and propose new approaches. 


\section{ACKNOWLEDGMENT}

This work has been supported by the African Center of Excellence in Mathematical Sciences and Applications (CEA-SMA) project in Benin. The authors would like also to thank Prof. Samuel FOSSO WAMBA (Toulouse Business School, France) for his invaluable suggestions, and Esther CHABI ADJOBO (IMSP, Benin) for her efforts in establishing the questionnaire and in participating in directing the surveying. They finally thank Prof. Tiémoman Koné and his team for having facilitated the surveys in Ivory Coast, and the anonymous referees for their useful comments, suggestions and edits. 


\section{REFERENCES}

Africa Food Business. (2019). Leading cocoa producer, Ivory Coast, adopts new cocoa trading system. Retrieved from https://www.foodbusinessafrica.com/2019/02/16/leading-cocoa-producer-ivory-coast-adopts-new-cocoatrading-system/

Alharby, M., \& van Moorsel, A. (2017). Blockchain-Based Smart Contracts: A systematic mapping study. In Proceedings of the Third International Conference on Artificial Intelligence and Soft Computing (IPDCA 2017) (pp. 125-140). Retrieved from https://www.doi.org/10.5121/csit.2017.71011

Brown, S. A., Dennis, A. R., \& Venkatesh, V. (2010). Predicting collaboration technology use: Integrating technology adoption and collaboration research. Journal of Management Information Systems, 27(2), 9-53. doi:10.2753/MIS0742-1222270201

Coabiso (2011). Cocoa farming: An overview. Retrieved from https://cocoainitiative.org/wp-content/ uploads/2016/09/ECA_-_2011_-_Cocoa_Farming_an_overview.pdf

Davis, F. D. (1989). Perceived usefulness, perceived ease of use, and user acceptance of information technology. Management Information Systems Quarterly, 13(3), 319. doi:10.2307/249008

Duncan, R. (2016). A first: Cotton shipped to China using a Blockchain-Based Smart Contract. Silicon angle. Retrieved from https://siliconangle.com/2016/10/24/worlds-first-claimed-as-cotton-shipped-to-china-usingblockchain-based-smart-contract/

Feed the Future Enabling Environment for the Food Security Project. (2019). Food safety and trade: The role of traceability systems. Retrieved from https://www.agrilinks.org/post/food-safety-and-trade-role-traceabilitysystems

Florentin, T. (2019). Le Benin premier producteur du coton en Afrique de l'Ouest. Retrieved from https://news. orificegroup.net/index.php/2019/05/22/benin-economie-le-benin-premier-producteur-du-coton-en-afrique-delouest/

Gauba, A. (2018). Finality in blockchain consensus. Retrieved from https://medium.com/mechanism-labs/ finality-in-blockchain-consensus-d1f83c120a9a

Gunnar, P., \& Ivan, D. (2019). Smart contracts for smart rural supply chains. Bulgarian Journal of Agricultural Science, 25(3), 454-463.

Hair, J. F., Jr., Hult, G. T. M., Ringle, C. M., \& Sarstedt, M. (2017). A primer on partial least squares structural equation modeling (2nd ed.). Sage Publications. doi:10.1016/j.lrp.2013.01.002

Holotescu, C. (2018). Understanding Blockchain technology and how to get involved. In Proceedings of the eLSE 2018 Conference (pp. 275-283). Academic Press. Retrieved from https://www.researchgate.net/ publication/324209739_Understanding_Blockchain_Opportunities_and_Challenges

Ioannis, K., Maria, P., \& Nedaa, B. A. (2018). Design of the blockchain smart contract: A use case for real estate. Journal of Information Security, 9(3), 177-190. doi:10.4236/jis.2018.93013

Joe, F. H., Jeffrey, J. R., Marko, S., \& Christian, M. Ringle. (2019). When to use and how to report the results of PLS-SEM. European Business Review, 31(1). doi:10.1108/EBR-11-2018-0203

KellyAnn. T. (2019). Tackling child labor in global supply chains. Retrieved from https://www.transparencyone. com/fr/tackling-child-labor-in-global-supplychains/

Koffman, T. (2019). Blockchain - Africa rising. Forbes. Retrieved from https://www.forbes.com/sites/ tatianakoffman/2019/04/04/blockchain-africa-rising/\#3f64cbc07711

Konstantinos, C., \& Michael, D. (2016). Blockchains and smart contracts for the Internet of Things. Special section editorial: The plethora of research in Internet of Things (IoT). IEEE Access, 4, 2292-2303. doi:10.1109/ ACCESS.2016.2566339

Laghmari, S. (2019). The upsurge of blockchain market in Africa. Retrieved from https://infomineo.com/theupsurge-of-blockchain-market-in-africa/ 
Luu, L., Chu, D.-H., Olickel, H., Saxena, P., \& Hobor, A. (2016). Making smart contracts smarter. In Proceedings of the 2016 ACM SIGSAC Conference on Computer and Communications Security (CCS '16) (pp. 254-269). ACM. doi:10.1145/2976749.2978309

Maciel, M. Q., \& Samuel, F. W. (2018). Blockchain adoption challenges in the supply chain: An empirical investigation of the main drivers in India and the USA. International Journal of Information Management, 46, 70-82. doi:10.1016/j.ijinfomgt.2018.11.021

Malan, M., \& Steyn, A. (2019). Implementing smart contracts in the syndicated loan market: An issue of adoption. IEEE Computer Society, 21(5), 39-47. doi:10.1109/MITP.2019.2929750

Maruping, L. M., Bala, H., Venkatesh, V., \& Brown, S. A. (2017). Going beyond intention: Inte grating behavioral expectations into the unified theory of acceptance and use of technology. Journal of the Association for Information Science and Technology, 68(3), 623-637. doi:10.1002/asi.23699

Mayer, R. C., Davis, J. H., \& Schoorman, F. D. (1995). An integrative model of organizational trust. Academy of Management Review, 20(3), 709-734. doi:10.5465/amr.1995.9508080335

Oakes, E. (2019). How blockchain technology is working to end child labor in the cocoa industry. See Change Magazine. Retrieved from https://www.seechangemagazine.com/?p=5644/

Olson, E., \& Tomek, J. (2017). Cryptocurrency and the blockchain: Technical overview and potential impact on commercial child sexual exploitation. Prepared for the Financial Coalition Against Child Pornography (FCACP) and the International Centre for Missing \& Exploited Children (ICMEC). Academic Press. Retrieved from https://www.icmec.org/wp-content/uploads/2017/05/ICMEC-FCACPCryptocurrencyPaperFINAL5-17.pdf

Shuai, W., Liwei, O., Yong, Y., Xiaochun, N., Xuan, H., \& Fei-Yue, W. (2019). Blockchain-enabled smart contracts: Architecture, applications and future trends. IEEE Transactions on Systems, Man, and Cybernetics, 49(11), 2168-2216.

Venkatesh, V., Morris, M. G., Davis, G. B., \& Davis, F. D. (2003). User acceptance of information technology: Toward a unified view. Management Information Systems Quarterly, 27(3), 425-478.

Venkatesh, V., Thong, J., \& Xu, X. (2012). Consumer acceptance and [the] use of information technology: Extending the unified theory of acceptance and use of technology. Management Information Systems Quarterly, 36(1), 157-178. doi:10.2307/41410412

World Vision. (2012). Forced [labor] and child labor in the cotton industry [fact sheet]. Retrieved from https:// campaign.worldvision.com.au/wp-content/uploads/2013/04/Forced-and-child-labour-in-the-cotton-industryfact-sheet.pdf 


\section{APPENDIX}

Table 10. The constructs

\begin{tabular}{|c|c|c|c|}
\hline Construct & Code & Indicators & Adapted From \\
\hline \multirow{4}{*}{$\begin{array}{l}\text { Social Influence } \\
\text { (SINF) }\end{array}$} & SI1 & $\begin{array}{l}\text { People who influence my behavior think that I should use Blockchain-Based Smart } \\
\text { Contract technologies }\end{array}$ & \multirow{4}{*}{$\begin{array}{l}\text { (Brown, Dennis \& } \\
\text { Venkatesh, 2010; } \\
\text { Marupinget al., } \\
\text { 2017; Venkatesh et } \\
\text { al.,2003, 2012) }\end{array}$} \\
\hline & SI2 & $\begin{array}{l}\text { People who are important to me think that I should use Blockchain-Based Smart } \\
\text { Contract technologies }\end{array}$ & \\
\hline & SI3 & $\begin{array}{l}\text { The use of Blockchain-Based Smart Contract technologies would be helpful to the } \\
\text { management team of the cocoa/cotton sector }\end{array}$ & \\
\hline & SI4 & $\begin{array}{l}\text { The cocoa/cotton sector generally has supported the use of blockchain-based } \\
\text { technologies }\end{array}$ & \\
\hline \multirow{4}{*}{$\begin{array}{l}\text { Facilitating } \\
\text { Conditions (FC) }\end{array}$} & $\mathrm{FC} 1$ & $\begin{array}{l}\text { The cocoa/cotton sector has the necessary resources to use some smart contract } \\
\text { technologies }\end{array}$ & \multirow{4}{*}{$\begin{array}{l}\text { (Brown et al., 2010; } \\
\text { Maruping et al., } \\
\text { 2017; Venkatesh et } \\
\text { al., 2003, 2012) }\end{array}$} \\
\hline & $\mathrm{FC} 2$ & I have the necessary knowledge to use Blockchain-Based Smart Contracts & \\
\hline & FC3 & Blockchain Technologies are not compatible with other systems we know of & \\
\hline & $\mathrm{FC} 4$ & $\begin{array}{l}\text { There is s help desk available for assistance in yhr case of blockchain-related } \\
\text { difficulties. }\end{array}$ & \\
\hline \multirow{3}{*}{$\begin{array}{l}\text { Performance } \\
\text { expectancy (PE) }\end{array}$} & PE1 & I think blockchain-based technology will help me in my job & \multirow{3}{*}{$\begin{array}{l}\text { (Brown et al., 2010; } \\
\text { Maruping et al., } \\
\text { 2017; Venkatesh et } \\
\text { al., 2003, 2012) }\end{array}$} \\
\hline & PE2 & $\begin{array}{l}\text { Using Blockchain-Based Smart Contract technologies will increase my productivity } \\
\text { through financing }\end{array}$ & \\
\hline & PE3 & $\begin{array}{l}\text { Using Blockchain-Based Smart Contract technologies will reduce child labor in the } \\
\text { sector }\end{array}$ & \\
\hline \multirow{2}{*}{$\begin{array}{l}\text { Blockchain-Based } \\
\text { Smart Contract } \\
\text { Usage (BSCU) }\end{array}$} & BSCU1 & $\begin{array}{l}\text { I believe blockchain-enabled smart contract actors will provide access to information } \\
\text { regarding how the technologies and their applications work. }\end{array}$ & \multirow{2}{*}{$\begin{array}{l}\text { Duncan, 2016; } \\
\text { Oakes, 2019; Maciel } \\
\text { \& Samuel, 2018) }\end{array}$} \\
\hline & BSCU2 & $\begin{array}{l}\text { I think I have the opportunities to provide feedback on blockchain-enabled smart } \\
\text { contract technologies and applications }\end{array}$ & \\
\hline \multirow{3}{*}{$\begin{array}{l}\text { Trust of Sector } \\
\text { Actors (TSA) }\end{array}$} & TSA1 & I believe I can trust some actors of the sector & \multirow{3}{*}{$\begin{array}{l}\text { Mayer et al., 1995; } \\
\text { Maciel \& Samuel, } \\
\text { 2018) }\end{array}$} \\
\hline & TSA2 & I think the actors in the sector are trustworthy. & \\
\hline & TSA3 & $\begin{array}{l}\text { I think the actors of the sector can be trusted to provide accurate information regarding } \\
\text { combating child labor. }\end{array}$ & \\
\hline \multirow{4}{*}{$\begin{array}{l}\text { Perceived Ease of } \\
\text { Use (PEOU) }\end{array}$} & PEOU1 & $\begin{array}{l}\text { I believe Blockchain-Based Smart Contract technologies will be easy for me to } \\
\text { understand }\end{array}$ & \multirow{4}{*}{$\begin{array}{l}\text { (Davis, 1989; Maciel } \\
\text { \& Samuel, 2018) }\end{array}$} \\
\hline & PEOU2 & I can be confused when using Blockchain-Based Smart Contract technologies. & \\
\hline & PEOU3 & Interacting with blockchain-based technologies can be frustrating. & \\
\hline & PEOU4 & Errors can be made when using blockchain-based smart-contract technology & \\
\hline \multirow{3}{*}{$\begin{array}{l}\text { Behavioral } \\
\text { Intention (BI) }\end{array}$} & BI1 & I intend to make use of Blockchain-based smart contracts in the following months & \multirow{3}{*}{$\begin{array}{l}\text { Brown et al., 2010; } \\
\text { Maruping et al., } \\
\text { 2017; Venkatesh } \\
\text { et al., 2003, 2012; } \\
\text { Maciel \& Samuel, } \\
\text { 2018) }\end{array}$} \\
\hline & BI2 & I predict I would use Blockchain-based smart technologies in the following months & \\
\hline & $\mathrm{BI} 3$ & I plan to use Blockchain-based smart technologies in the following months & \\
\hline \multirow{3}{*}{$\begin{array}{l}\text { Behavioral } \\
\text { Expectation (BE) }\end{array}$} & BE1 & I expect to use of Blockchain-based smart contracts in the following months & \multirow{3}{*}{$\begin{array}{l}\text { Maciel \& Samuel, } \\
\text { 2018) }\end{array}$} \\
\hline & BE2 & I will use Blockchain-based smart contract technologies in the following months & \\
\hline & BE3 & $\begin{array}{l}\text { I am likely to use Blockchain-based smart contract technologies in the following } \\
\text { months. }\end{array}$ & \\
\hline
\end{tabular}


Senou Rosaire is a Ph.D. student at the Institute of Mathematics and Physics (IMSP), University of Abomey-Calavi, Benin. He received a bachelor's degree in telecommunications at Ghana Technology University College (2011) and a Master Degree at IMSP (2018) where he majored in networking and information systems. He also became a Cisco Certified Network Associate (2011) and received his Advanced Diploma certificate from the City and Guilds of London Institute (2007) in telecommunications. He has more than five years of professional experience in networking and telecommunications and has worked in companies such as Huawei where he was in charge of conducting surveys for Wi-Fi network implementation; supervising fiber network deployment contractors onsite; and proposing solutions to customers. His research embraces networking and blockchain technologies.

Jules Dégila (Ph.D.) is a Senior Lecturer at the University of Abomey-Calavi, Benin. He is specialized in the optimization of telecommunication networks and systems architecture, deployment, and operations. During the last ten years, he has held different management, executive, and board member's positions for Western and African telecommunications companies. A guest speaker at various universities in the fields of operations research and telecommunication, he has also advised many companies and governments as a strategist in real-time communications and internet protocol (IP) networking. From 04/2005 to 06/2010, he was an Assistant Director of Telecommunications Applications, and Technologies for a leading Canadian analog and digital television, high-speed Internet, and telephony services provider. During his career in Canada, he was responsible both for the technological architectures of all telecommunications services, and for exploring and developing advanced telecommunication applications and technologies. He served as a technology strategist for regulatory affairs, and was also a member of different working groups of CableLabs (a Denver, Colorado-based research consortium for cable operators). Jules received a Ph.D. degree in electrical engineering from École Polytechnique de Montréal, Canada in 2004. 